\title{
A PROBABILISTIC APPROACH TO FATIGUE RISK ASSESSMENT IN AEROSPACE COMPONENTS
}

\author{
G. CAVALLINI ${ }^{1} \&$ R. LAZZERI ${ }^{2}$ \\ ${ }^{1,2}$ Department of Aerospace Engineering - University of Pisa, Italy
}

\begin{abstract}
This paper describes a new possible approach to fatigue design of aerospace components founded on probabilistic bases compared with safe life and damage tolerance that are founded on deterministic bases. A numerical tool have been introduced and explained together with the experimental activity for its validation analyses.

For a typical aerospace component, such as a lap joint panel, an acceptable maximum risk level has been established and the maintenance program has been planned to ensure operating life without catastrophic failures.
\end{abstract}

The analysis has shown that this new approach introduces several benefits in fatigue design.

\section{INTRODUCTION}

The fatigue design of aerospace components is presently approached by using damage tolerance or - if unusable - safe life criteria. Both approaches are applied on deterministic bases, while fatigue phenomena have a deep stochastic behavior that must be taken into account. So, high safety factors must be introduced, that can cause heavy structures and/or short lives between subsequent maintenance actions. In spite of this, the risk level remains unknown and dangerous configurations, such as multiple site damage, could not be considered.

A different approach, founded on probabilistic bases, could introduce several advantages. Indeed, the risk level can be controlled and so the applied safety factors can be adequate and maintenance actions can be well planned.

On the other side, this approach can be used only if a deep knowledge of the statistical characteristics of the design variables is achieved and reliable analytical models for fatigue behavior are available; and anyway a wide validation activity is needed to reach adequate confidence levels.

To evaluate the probability of failure, it is necessary to have available a lot of failure data. It is obvious that it is not possible to obtain them by means of experimental tests, but it is necessary to use numerical tools for their simulation. So, a software code, the PISA (Probabilistic Investigation for Safe Aircraft) code, [1], has been developed and tuned up to describe the behavior of fatigue cracks, from the nucleation up to the final failure, for typical aerospace components, such as the lap-joint panels.

The nucleation phase has a strong influence on the fatigue life and it can be described by means of the EIFS (Equivalent Initial Flaw Size) approach, that allow to consider the life as a unique propagation phase from time zero to the final failure. This "unified" approach yields, first of all, significant simplifications in the procedure and this is very important because the calculations must be repeated many times, again and again.

To support and validate this approach, a wide experimental activity on simple coupons and complex components has been carried out to characterize the EIFS distribution and to allow the employment of this distribution in the prediction of the crack dimensions at assigned number of cycles and the final failure. 
In this paper, it is shown that the approach is consistent and the tool can predict well the fatigue behavior.

\section{THE PISA CODE}

The PISA code, Figure 1, evaluates the probability of failure of typical aerospace components, such as the riveted lap-joints. It simulates the fatigue behavior from the nucleation of the cracks and their growth up to the final failure. If needed, planned maintenance actions can also be introduced. At present, the stochastic behavior of the phenomenon is described through four variables:

\section{- $\quad$ the EIFS,}

- $\quad$ the $\mathrm{C}$ parameter of the Paris law,

- $\quad$ the fracture toughness $\mathrm{K}_{\mathrm{Ic}}$,

- $\quad$ the probability of crack detection by means of a non destructive inspection method, POD.

All these distributions are arranged together by means of the MonteCarlo method, that allows the introduction of further distributions, if needed.

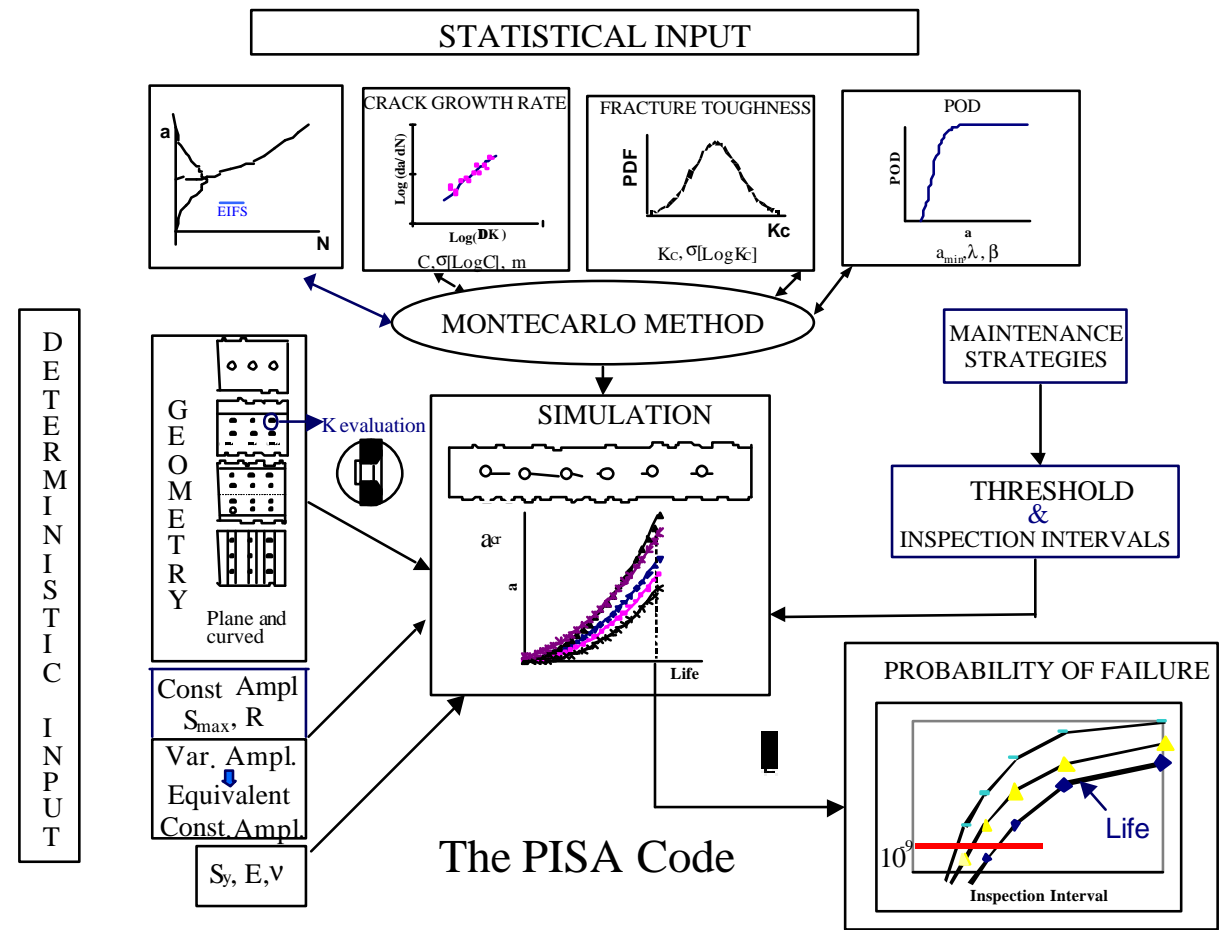

Figure 1: Structure of the code

The crack nucleation is resolved by assigning at each side of the holes a dimension for the crack at time $\mathrm{t}=0$, extracted from the EIFS distribution. 
For the crack growth, the simple Paris law $\frac{d a}{d N}=C \Delta K^{m}$ is implemented and the stress intensity factor $\mathrm{K}$ is evaluated by separating the contribution due to uniform stress $\mathrm{S}_{\infty}$ and that due to the pin loads $\mathrm{P}_{\mathrm{i}}$, [2], [3]:

$$
\mathrm{K}=\frac{1}{2} \cdot \mathrm{CR}_{\text {tot }} \cdot\left(\mathrm{S}_{\infty}+\mathrm{S}_{\text {bypass }}\right) \cdot \sqrt{\pi \cdot \mathrm{a}}+\frac{1}{2} \cdot \mathrm{CP}_{\text {tot }} \cdot \mathrm{p} \cdot \sqrt{\pi \cdot \mathrm{a}}
$$

$\mathrm{S}_{\text {bypass }}$ is the stress transferred by the rivets, $2 \mathrm{a}$ the crack length and $\mathrm{p}$ a uniform pressure on the hole, due to the rivet, [3].

The $\mathrm{CR}_{\mathrm{i}}$ and $\mathrm{CP}_{\mathrm{i}}$ corrective factors are functions of the boundary conditions such as: holes, other cracks, finite panel, and so on. They are compounded together to obtain $\mathrm{CR}_{\mathrm{tot}}$ and $\mathrm{CP}_{\mathrm{tot}}$, [2].

According to the Swift criterion, two collinear cracks are considered linked when their plastic radii are tangential. Failure can be caused by the reaching of yielding stress or fracture toughness.

\section{EVALUATION OF THEEQUIVALENT INITIAL FLAW SIZE DISTRIBUTION}

To support this approach and to validate the analytical models implemented inside the PISA code, a wide experimental activity was performed on 2024T3 specimens. The tests were stopped at assigned number of cycles, the specimens were statically broken and the crack dimensions were carefully measured. The crack sizes obtained in simple strip lap-joint, Figure 2, fatigue tests under constant amplitude load spectrum with $\mathrm{S}_{\max }=120 \mathrm{MPa}$ and $\mathrm{R}=0.1$ were used to characterize the EIFS distribution by means of a draw back procedure, [4], that can provide the 'equivalent' initial crack dimension by using a fictitious 'negative' integration from experimental number of cycles till to $\mathrm{N}=0$.

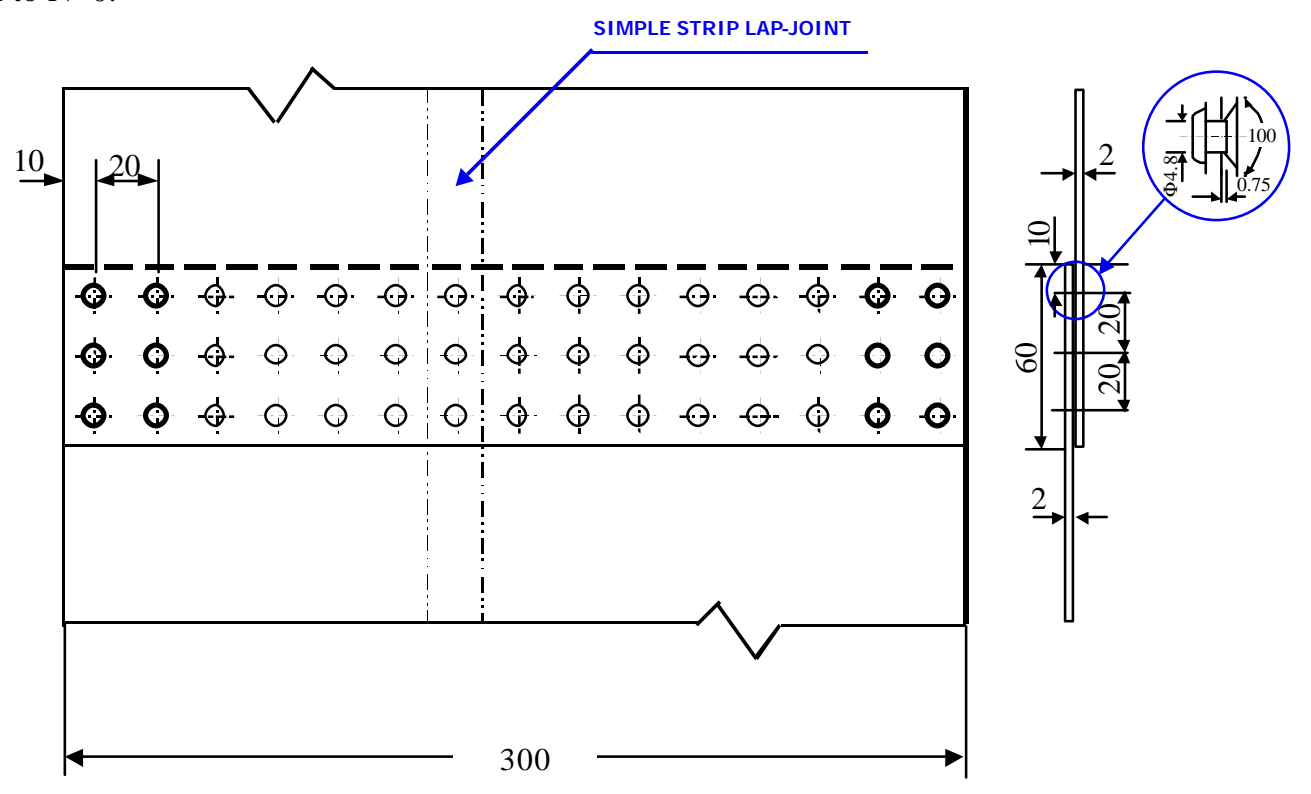

Figure 2: Specimen geometry 
For the draw-back procedure, it was used the PISA code and the model of a specimen with a through crack at a lap-joint, taking into account the effects of membrane stress, by-pass loading and pin load, but not the effect of the rivet interference and the true value of the secondary bending, [5]; this is also the model used to describe the growth ahead the "nucleation". The effects of the rivet interference and the true value of the secondary bending will be estimated all together as a single effect in the Equivalent Initial Flaw Size.

The $\mathrm{C}$ and $\mathrm{m}$ values used for the draw back and for the crack growth are $\mathrm{C}=7 \mathrm{E}-8, \mathrm{~m}=3.0781$, $[\mathrm{dc} / \mathrm{dN}]=\mathrm{mm} /$ cycles, $[\Delta \mathrm{K}]=\mathrm{MPa}(\mathrm{m})^{0.5}$, obtained during a previous research activity for $2024-\mathrm{T} 3$, in the long crack range. The EIFS was supposed to fit a lognormal distribution, with $\mu\left[\log \left(\mathrm{c}_{0}\right)\right]=-$ 2.88605, and $\sigma\left[\log \left(\mathrm{c}_{0}\right)\right]=0.28456,[6]$, obtained from the previous described experimental tests on simple strip lap-joints.

\section{DAMAGE EVALUATION IN COMPLEX GEOMETRIES}

Further experimental tests were carried out on wide lap-joint panels, in 2024-T3, Figure 2, under constant amplitude load spectrum $\left(\mathrm{S}_{\max }=120 \mathrm{MPa}, \mathrm{R}=0.1\right)$. Starting from the EIFS distribution and by using the PISA code, the capability of the procedure has been verified by simulating the behavior of the lap-joint panels.

The comparison has been made by generating 1000 runs, i.e. by simulating the crack sizes at different number of cycles in 1000 lap-joint panels similar to the tested lap-joint panels. In Figure 3 it is shown the comparison between the predicted crack dimensions and the corresponding experimental results at 80000 cycles. The run-out effect has been introduced inside the crack size distributions by using the maximum likelihood method. Their crack dimensions have been supposed less than $0.1 \mathrm{~mm}$, that is the smaller dimension that could be seen during this experimental activity by using the available non destructive inspection methods.

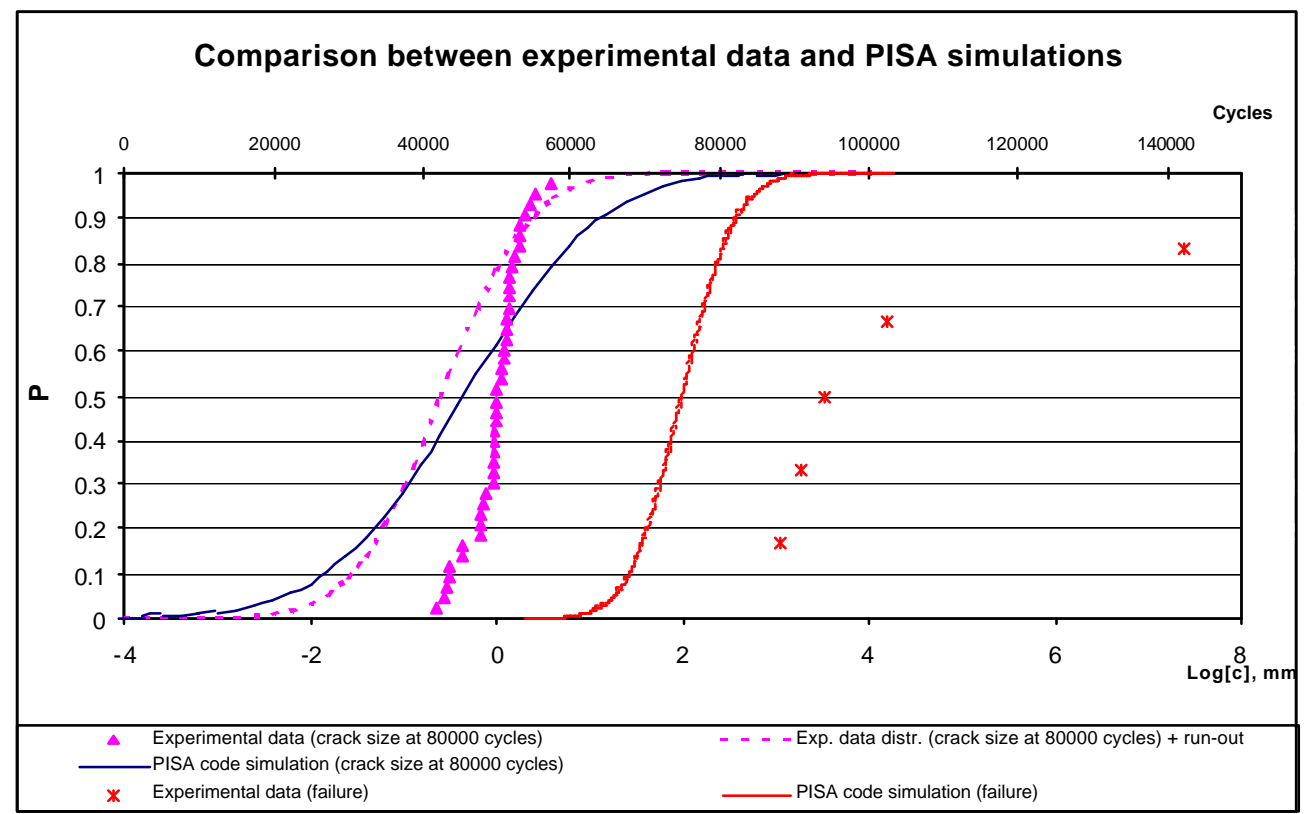

Figure 3: Experimental and numerical results 
Concerning with the distribution of the crack sizes at a fixed number of cycles, it can be seen the agreement between predictions and experimental results; in detail the predicted distribution is included between the experimental data distribution with and without the run-outs.

The final validation was the comparison between the predicted number of cycles to failure and the experimental failure data in wide lap joint panels, that is shown in Figure 3. Indeed, the simulation of the failure of the panels is conservative because a little earlier failures are predicted.

\section{COMPARISON BETWEEN DETERMINISTIC AND PROBABILISTIC APPROACH}

In Figure 4 the comparison between the use of the deterministic and probabilistic approach is shown.

The use of the safe life criterion for the fatigue design of the wide lap-joint panel means that the component must be replaced at a number of cycles that is a portion of the mean life, i.e. the life of the $50 \%$ of the tested components. So, if a safety factor equal to 4 is introduced, at $74550 / 4=18637$ cycles the component must be substituted. The corresponding probability of failure is excessively low (excessively less than $10^{-7}$, that is a generally accepted value for the risk level), so the safety factor is very conservative and the structure could be over sized.

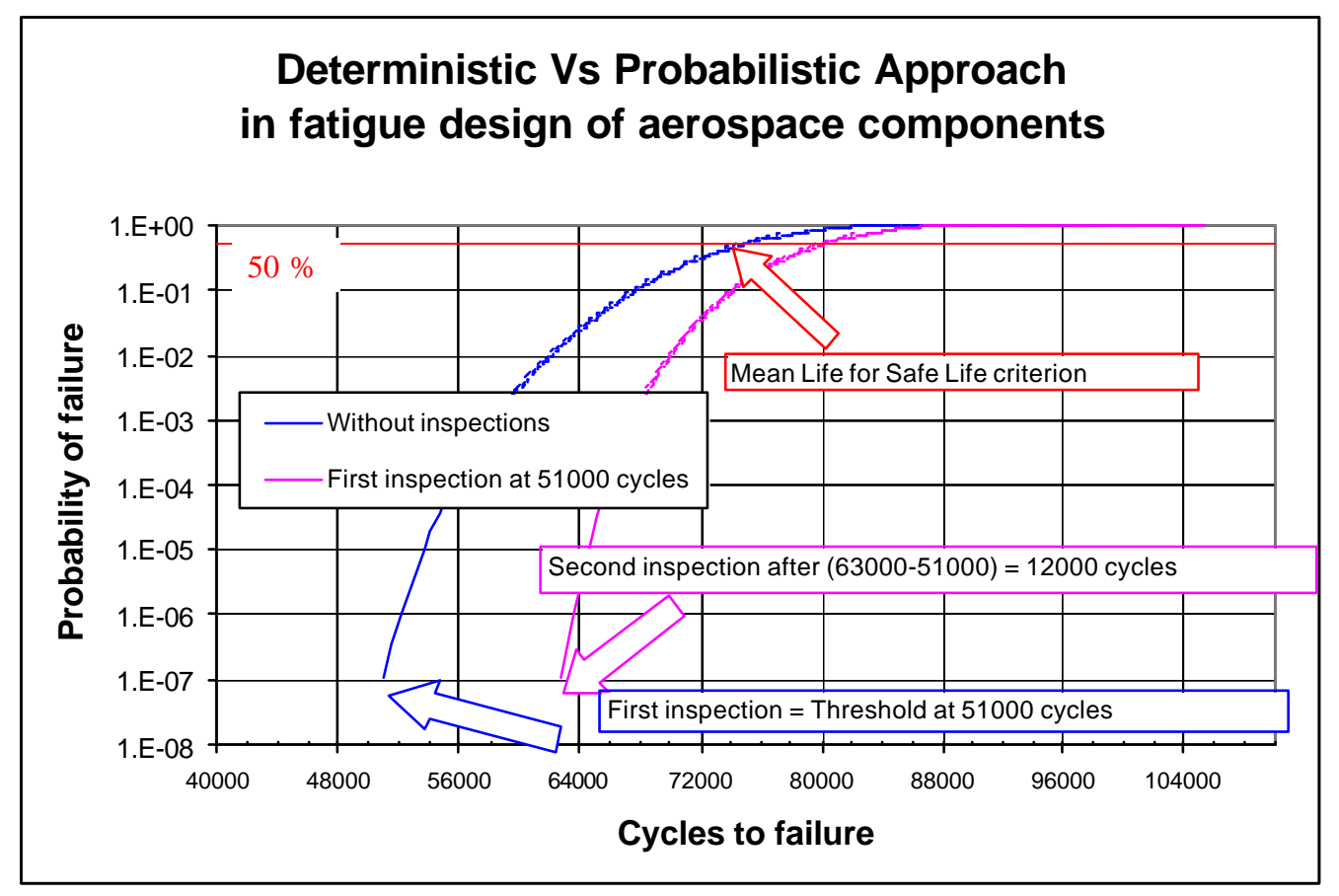

Figure 4: Probability of failure obtained by using the PISA code

The damage tolerance criterion states that to fix the first inspection (threshold) must be considered the number of cycles to failure of a deterministic rogue crack that grows starting from $1.27 \mathrm{~mm}$ size. Next inspections must be fixed by considered the growth of a surely detectable crack $(6.35$ 
$\mathrm{mm}$ size) till to the final failure. A safety factor must be applied to the corresponding number of cycles and it should be equal to 2 or 3 . For this component, the growth period of a $1.27 \mathrm{~mm}$ crack to the final failure is equal to 57700 cycles and the growth period of a $6.35 \mathrm{~mm}$ crack to the final failure is equal to 31100 cycles.

By applying a safety factor equal to 2 for the threshold and equal to 3 for the following inspections, the first inspection must be done at $57700 / 2=28850$ cycles and the next at $31100 / 3=10388$ cycles. The corresponding risk levels are very low. Unfortunately, this is not a general result and usually the risk levels are not known.

On the contrary, the probabilistic approach can fix the risk level, as an example $\mathrm{P}_{\mathrm{f}}=10^{-7}$. So, the threshold can easy be fixed at 51000 cycles and the second inspection at 63000 cycles, after 12000 cycles.

\section{CONCLUSIONS}

In this paper, a new possible approach to fatigue design of aerospace components is shown, founded on probabilistic bases, together with a tool - the PISA code - and the experimental test results used for the validation of the tool and of the approach.

The validation analysis provided good results and so the PISA code can be used for the risk assessment analysis and to compare the effect of the deterministic approaches (damage tolerance and safe life) with those of the probabilistic approach in the fatigue design of a wide lap-joint panel.

The advantages appeared to be very important:

- the probability of failure can be established as a design constraint (or goal), for instance $10^{-7}$; so it is well defined the risk level. In deterministic approaches, this important element is not known and the assumption of conservative values of the inputs can produce uneconomical designs without benefits,

- in each design condition, it is possible to know the "distance" from the critical condition in terms of probability of failure,

- the MSD phenomenon can be handled in a logical way because it is one of the possible statistical configurations.

The comparison between the different approaches applied to a lap joint panel shows that a more economic inspection plan can be applied if the probabilistic approach is used, without loss of safety.

[1] Lazzeri R. , “The PISA Code”, AEROTECNICA Missili e Spazio, Vol. 81-1/2002, pp. 17-25

[2] Kuo A., Yasgur D., Levy M., "Assessment of damage tolerance requirements and analyses -task I report”, ICAF Doc. 1583, AFVAL-TR-86-3003, Vol. II, AFVAL WrightPatterson Air Force Base, Dayton, Ohio, marzo 1986.

[3] Broek D., Sampath S., "Estimation of requirements of inspection intervals for panels susceptible to Multiple Site Damage", in Atluri, "Structural integrity of aging airplanes", Atluri Ed., 1991, pp 339-389.

[4] Lazzeri R., "Progetto a fatica: approcci tradizionali e nuove metodologie (risk level assessment)", Ph.D. Thesis, Dept. Of Aerospace Engineering, Pisa, 2003.

[5] Cavallini G., Lazzeri R., “Applicazione dell' approccio probabilistico all'analisi a fatica di giunti chiodati: metodologia e verifiche sperimentali”, XVII Congresso Nazionale AIDAA, vol. III, pp. 1733-1742, Roma, 2003. 
[6] Cavallini G., Lazzeri R., "Report on the validation of the numerical methods", ADMIRE Doc. N. ADMIRE-TR-5.2-96-5.1/UP, Dept. of Aerospace Engineering, Pisa, 2004. 